\title{
Effects of sevoflurane and desflurane on the blood and plasma viscosity Rauf Gul ${ }^{1}$, Denizhan Karis ${ }^{2}$, Guniz Meyanci Koksal ${ }^{3}$, Cem Sayilgan ${ }^{3}$, Murat Bolayirli ${ }^{4}$, Huseyin $\mathrm{Oz}^{3}$, Meltem Ercan ${ }^{4}$
}

\begin{abstract}
The purpose of present study was to compare the effects of desflurane and sevoflurane on blood viscosity in three different shear rates and plasma viscosity. Forty male patients, ASAI-II, undergone tympanoplasty were included in this study. Patients were randomly categorized as anaesthetized either with sevoflurane or desflurane. Anaesthesia was maintained with inspiratory concentrations of sevoflurane 1-1.5 MAC or desflurane. The samples were taken for hemorheological and biochemical examinations before induction of anaesthesia (initial time) and at $60^{\text {th }}$ and $120^{\text {th }} \mathrm{min}$ of the operation. Blood viscosities were measured by rotational viscometer. Plasma viscosity was measured by capillary viscometer. Patients receiving desflurane showed steady decrease at $231 / \mathrm{sec}$ shear rate at $60^{\text {th }}$ and $120^{\text {th }} \mathrm{min}$ and in blood viscosity at $1151 / \mathrm{sec}$ shear rate in $120^{\text {th }} \mathrm{min}$.

Statistically significant decrease in the level of plasma viscosity was observed in the patient group anesthetized with desflurane, between initial time vs $60^{\text {th }} \min (\mathrm{p}<0.01)$, initial time vs $120^{\text {th }}$ min. $(p<0.01)$. Desflurane produced stable effects on the blood circulation. The differences in the blood viscosity should not be overlooked.
\end{abstract}

Keywords: Desflurane, Sevoflurane, Blood viscosity, Plasma viscosity

\section{Introduction}

General anaesthesia is a medically combination of analgesia, loss of consciousness and protective reflexes resulting from the administration of one or more general anaesthetic agents. Inhalation or nonvolatile agents are used to induct and to maintain general anesthesia or to relieve pain or to suppress the response and to control the changes in breathing drastically.

General anasethtetic agents do not have a specific pharmacological structure, instead their effects can be also observed in other organs except central nervous system. General anaesthesia has different cardiovascular effects, including its partial effect on anaesthetics of heart and blood vessels [1]. Microcirculatory parameters are altered by the most anaesthetics agent used for induction and during the anaesthesia process. These parameters have effects on the vasoactivity [1-3], blood pressure [4, 5] cardiac output [6] and vascular resistance [7].

It is well known that systemic circulation regulates tissue blood flow and local tissue oxygen diffusion, and has a key role in the development of numerous disease and dysfunctions [8]. Blood flow characteristics, which are also defined as blood viscosity, are directly affected by the physical features of blood. The hemodynamic changes of blood have a significant effect on the vascular system. Blood viscosity is one of the major determinants of blood flow and can be directly related to cardiovascular disease. Since blood is a non-Newtonian fluid, the viscosity of blood depends on the factors such as shear force and shear rate of the blood. As the speed of blood flow decreases, blood viscosity increases. Mediators of blood viscosity include hematocrit, red blood cell deformability, red blood cell aggregation, and plasma viscosity $[9,10]$. These mediators of blood viscosity differ according to diameters of vessels.

There are many studies that investigate the advantages or disadvantages of volatile anaesthetics to choose more appropriate and less harmful anaesthetics $[11,12]$. The potent inhalation anaesthetics currently used in clinical practice have similar effects in regional tissue perfusion and microcirculation under stable anaesthetic conditions, but these effects may be different under pathophysiologic conditions such as hemorrhage, sepsis, or during surgical operations [13]. Anaesthetics have been studied by many different issues, but little has been written about the anaesthetics' hemoreological effects. 
Considering the wide use of anaesthetics' in daily practice importance of the study on desflurane and sevoflurane becomes more clear. Sevoflurane and desflurane are widely used clinical volatile anaesthetics that provide a greater degree of control of anaesthetic depth and a more rapid immediate recovery from anesthesia than is currently available with other inhaled agents because of their decreased solubility [14]. The aim of the study was to compare the effects of desflurane and sevoflurane on the changes of time dependent blood viscosity.

\section{Materials and Methods}

This study was approved by the Human Studies Review Board of the Cerrahpasa Medical Faculty of Istanbul University, and informed consent forms were received from all patients. The cycle variations of women life may have effects over hormones and hemodynamic features. The hematocrit concentration, hormonal status and liquid/fat distribution are more standardized among men. Thus, forty male patient aged 20-45 year, ASA I-II, undergone tympanoplasty procedure were enrolled to this study. The decision of tympanoplasty procedure was chosen according to the fact of the limited chance of probable bleeding, and its minor effects on hemodynamic and hormonal status and the close amounts of liquid exchange. Patients were randomly selected as either anaesthetized with Group sevoflurane (Group S: n=20) or desflurane (Group D: $\mathrm{n}=20$ ).

Exclusion criteria were performed for the patients with abnormal preoperative laboratory data (electrolyte imbalance, anemia, polycythemia, thrombocytopenia, leucopenia, and leukocytosis), chronic hypertension, diabetes, hematologic diseases, kidney diseases, anticoagulant and antiagregant treatment history and macro molecular fluid infusion. Moreover, the patients who were faced with major bleeding during the operation were also excluded from the study.

Premedication was done by midazolam 0.03 $\mathrm{mg} / \mathrm{kg}$ IV (Dormicum, ROCHE). Monitoring consisted of continuous measurement of electrocardiogram (ECG), peripheral arterial oxygen saturation by pulse oxymetry $\left(\mathrm{sPO}_{2}\right)$, non invasive blood pressure (NIBP) and end-tidal $\mathrm{PCO}_{2}\left(\mathrm{ETCO}_{2}\right)$ and inhaled anaesthetic gas concentrations (Millenia 3500; Vital Signs, Parway, Orlando, FL, USA)

A $20 \mathrm{G}$ IV cannula was inserted into a dorsum of hand for fluid infusion and another $18 \mathrm{G} \mathrm{IV}$ cannula was inserted into brachial vein (opposite side of the body) for blood sampling. Fluid balance of the patients was the supply of the continuous requirement and the loss of fluid (urine, hemorrhage and insensible loss) during operation. Thus, the tympanoplasty procedure was chosen as a study group to limit the hemorrhage probability and to minimalize the liquid loss. Balanced salt solutions were given intraoperatively $(0.9 \% \mathrm{NaCl}, 2 \mathrm{~mL} / \mathrm{kg} / \mathrm{h})$. Dehydrated and over-hydrated patients were excluded from the study.
Central venous pressure was not assessed in our study. The total liquid concentrations were not included in the study.

In both groups, anaesthesia was performed with propofol $2 \mathrm{mg} / \mathrm{kg}$, morphine $0.1 \mathrm{mg} / \mathrm{kg}$ intravenously, and orotracheal intubation was facilitated with cis-atracurium $0.2 \mathrm{mg} / \mathrm{kg}$. Patients lungs were ventilated with $40 \%$ oxygen in air at a frequency of 12 breaths/min and tidal volume adjusted to maintain $\mathrm{ETCO}_{2}$ at $4.6-5.3 \mathrm{kPa}\left(\mathrm{V}_{\mathrm{T}}, 6-8 \mathrm{~mL} / \mathrm{kg}\right)$. Anaesthesia was maintained either with sevoflurane at an inspiratory concentration of 2-3\% (1-1.5 minimum alveolar concentration (MAC)), or desflurane $6-9 \%$ (1-1.5 MAC). Minimum alveolar concentration is the concentration of the vapour in the lungs that is needed to prevent motor response in $50 \%$ of subjects in response to surgical stimulus. It is median value used to compare the strengths, or potency, of anaesthetic gasses. A lower MAC value represents more potent volatile anesthetic. Incremental cis-atracurium doses were administered regularly in order to maintain the neuromuscular block and MAC follow-up was held by means of percentages on the monitor in the operating room.

In our study, patients' venous blood samples were withdrawn before (baseline) and $60^{\text {th }}, 120^{\text {th }} \mathrm{min}$ of the operation. Systolic artery pressure (SAP) and diastolic artery pressure (DAP) as $\mathrm{mmHg}$ of the patients recorded at blood sampling time. The duration of the operation did not have any importance, as the hemodynamic features were followed up for 120 minutes. On fasting venous blood for hemorheological measurements was sampled in (K+EDTA) tubes in resting conditions. Hemorheological (blood and plasma viscosity) parameters examinations were made in Istanbul University, Cerrahpasa Medical Faculty, Biophysics Department. Blood viscosity samples were measured by 'Wells-Brookfield cone-plate rotational viscometer, with CP-40 spindle (LVDV III Brookfield engineering LTD; USA) at three shear rates (23 1/sec, $1151 / \mathrm{sec}, 2301 / \mathrm{sec})$.

Viscosity measurements were made according to "New guidelines for hemorheological laboratory techniques" [15]. Blood viscosity values were corrected to a hematocrit of $45 \%$ by a regression equation [16]. These adjusted blood viscosity values were termed as corrected blood viscosity, and were reported at shear rates of 23,115 , and $2301 / \mathrm{sec}$. Blood samples were centrifuged $15 \mathrm{~min}$ at $3000 \mathrm{rpm}$ and divided into multiform element for plasma viscosity measurement. Derived plasma viscosity was measured by Harkness capillary viscometer (Coulter Electronics LTD England) [17].

Plasma viscosity does not vary with shear rate, as it behaves like a Newtonian fluid. Blood and plasma viscosity measurements were made at $37^{\circ} \mathrm{C}$ and data were expressed as milipascal second (mPa.s). Biochemical studies were performed by routine laboratory procedures in Cerrahpasa Medical Faculty, Biochemistry Department, Fikret Biyal Laboratory. During the study, $4-5 \mathrm{ml}$ blood (K+ EDTA) for hemogram, blood and plasma viscosity, total 
cholesterol fibrinogen $3 \mathrm{ml}$ blood (dry tube) for total protein and albumin was taken. Fibrinogen levels were measured with Dade Behring BCT optic Reader (Dade Behring Tech. Germany) and data were expressed as $\mathrm{mg} / \mathrm{dl}$. Hematocrit was measured with BeckmannCoulter HMX apparatus and total protein and albumin were measured with Olympus Au 800 (MITSUCHI Olympus Tech, Japan) and the data were expressed as $\mathrm{g} / \mathrm{dl}$.

\section{Statistical Analyses}

Data are expressed as mean \pm standard deviation (SD). Demographic and biochemical variables between the groups were compared using unpaired student t-tests. Hemorheological variables (Blood viscosity, corrected blood viscosity, plasma viscosity) were analyzed using two-way ANOVA with repeated measurement (Comparison of between two groups) and one-way ANOVA with repeated measurement (intra-group comparisons). For analysis of blood viscosity, univariate two-way analysis of covariance (ANCOVA) was done with three different shear rate and time as the covariates. Post hoc analysis was performed with the Bonferroni/Dunn correction. The values of $p<0.05$ were considered significant. All statistical analysis was performed using the statistical analysis software package SPSS 11.0 for Windows.

\section{Results}

This study consisted of two groups as Group $\mathrm{S}$ and Group D. There were no differences between two groups in demographic data (Table 1). Data from the sevoflurane and desflurane groups are given on Table 2 and Table 3, respectively. The hemorheological and biochemical parameters in the tables are expressed as mean values \pm SD. Each groups' measurements were repeated in three certain times as initial time, $60^{\text {th }}$ min. and $120^{\text {th }}$ min., respectively.

Table 1. Patients characteristics

\begin{tabular}{|c|c|c|c|}
\hline \multirow[t]{2}{*}{ Group } & Age & Weight & Height \\
\hline & $(\mathrm{yr})$ & $(\mathrm{kg})$ & $(\mathrm{cm})$ \\
\hline Group S $(n=20)$ & $31 \pm 5$ & $71 \pm 9$ & $162+5$ \\
\hline Group D $(n=20)$ & $29 \pm 3$ & $70 \pm 7$ & $163 \pm 4$ \\
\hline
\end{tabular}

Data tested by t-test: mean+SD, Group S; Sevoflurane Group, Group D; Desflurane Group.

In the patients who were received the sevoflurane, we observed a significant decrease in the value of SAP, DAP and MAP at initial time vs $60^{\text {th }}$ min. $(p<0.001, p<0.001$ and $p<0.001$, respectively $)$ and $120^{\text {th }}$ min. $(p<0.001, p<0.001$ and $p<0.001$, respectively). Patients received desflurane showed significant decrease in the value of SAP, DAP and MAP at initial time vs $60^{\text {th }}$ min. $(p<0.001, p<0.001$ and $\mathrm{p}<0.001$, respectively) and $120^{\text {th }} \mathrm{min}$. $(\mathrm{p}<0.001$, $\mathrm{p}<0.001$ and $\mathrm{p}<0.001$, respectively).

When the blood viscosity was measured at its native hematocrit level in the patients anesthetized with sevoflurane, we noted that a significant reduction in the level of blood viscosity at $231 / \mathrm{sec}$ and 230 $1 /$ sec shear rates in the following time periods in both $60^{\text {th }}$ min . $(p<0.001$ and $p<0.05$, respectively $)$ and $120^{\text {th }}$ min. $(\mathrm{p}<0.01$ and $\mathrm{p}<0.05$, respectively) samples (Table 2). Likewise, in the patients who were received the Group S, we observed a significant decrease in the level of blood viscosity in the shear rate is $1151 / \mathrm{sec}$ at initial time vs $60^{\text {th }} \mathrm{min}$. $(\mathrm{p}<0.01)$. After hematocrit $45 \%$ was standardized, there was no statistically significant in the level of blood viscosity at three shear rate $(23,115$ and $2301 / \mathrm{sec})$ in patients anesthetized with Group S (Table 3).

Patients received desflurane showed a meaningful decrease at $231 / \mathrm{sec}$ shear rate in $60^{\text {th }} \mathrm{min}$ $(p<0.05)$ and an important decrease at $120^{\text {th }} \mathrm{min}$. $(p<0.01)$ and also in the level of blood viscosity in 115 $1 /$ sec shear rate at $120^{\text {th }} \mathrm{min} .(\mathrm{p}<0.01)$. There was no a statistically significant difference observed in the level of blood viscosity at $230 \mathrm{1} / \mathrm{sec}$ shear rate in patients anesthetized with desflurane (Table 3). After hematocrit $45 \%$ was standardized, there was only a meaningful reduction in blood viscosity in $231 / \mathrm{sec}$ shear rate at initial time vs $120 \mathrm{~min} .(\mathrm{p}<0.05)$ in the patients anesthetized with desflurane (Table 3 ).

In our study, time-dependant changes of measured parameters were calculated by their division to initial values and the results were expressed as change ratio. To conclude that Group $\mathrm{S}$ had a decreased blood viscosity compared to desflurane, we calculated data on decrease rate of blood viscosity in both Group S and Group D. Rate of change was shown as percentage change from initial value. The decrease ratio of blood viscosity from the Group $\mathrm{S}$ and Group D is given on Table 4. When the decrease ratio of blood viscosity was calculated at its native hematocrit level in the patients anesthetized with Group S, we noted that meaningful decreases in the level of blood viscosity at the all shear rates $(23,115$ and $2301 / \mathrm{sec})$ at initial time vs $60^{\text {th }} \mathrm{min} . \quad(\mathrm{p}<0.05$, $p<0.05$ and $p<0.05$ respectively) (Table 4 ). There was no a statistically significant difference observed on the rate of blood viscosity in both native and corrected hematocrit $(45 \%)$ at the all shear rates $(23,115$ and $2301 / \mathrm{sec}$ ) are at initial time vs $60^{\text {th }} \mathrm{min}$. and at initial time vs $120^{\text {th }} \mathrm{min}$. in patients anesthetized with desflurane (Table 4).

Although the level of plasma viscosity remained the same during measuring period in the patients anesthetized with Group S, statistically important decrease in the level of plasma viscosity was observed between initial time vs. $60 \mathrm{~min}$. $(p<0.01)$, initial time vs $120 \mathrm{~min} .(\mathrm{p}<0.01)$ in patients anesthetized with desflurane.

The value of hematocrit decreased in the patients anesthetized with Group $\mathrm{S}$ at $60^{\text {th }} \mathrm{min}$. $(\mathrm{p}<0.01)$ and $120^{\text {th }} \min$. $(\mathrm{p}<0.001)$. 
Table 2. Hemorheologic and hematologic values for sevoflurane group

\begin{tabular}{|c|c|c|c|}
\hline & Initial Time & $60^{\text {th }} \cdot \min$ & $120^{\text {th }} \cdot \min$ \\
\hline Hct $(\%)$ & $39.24 \pm 3.20$ & $37.84 \pm 3.34^{\mathrm{a}^{* *}}$ & $37.33 \pm 3.26^{\mathrm{a}^{* * *}}$ \\
\hline BV (230 1/sec, mPa.s) & $4.10 \pm 0.55$ & $3.82 \pm 0.39^{\mathrm{a}^{*}}$ & $3.89 \pm 0.34^{\mathrm{a}^{*}}$ \\
\hline BV (115 1/sec, mPa.s) & $5.95 \pm 0.94$ & $5.36 \pm 1.10^{\mathrm{a}^{* *}}$ & $5.58 \pm 1.12$ \\
\hline BV (23 1/sec, mPa.s $)$ & $7.07 \pm 1.30$ & $6.15 \pm 1.24^{\mathrm{a}^{* * *}}$ & $6.33 \pm 1.13^{\mathrm{a}^{* *}}$ \\
\hline \multicolumn{4}{|l|}{ Corrected Hct (45\%) } \\
\hline$\overline{\mathrm{BV}(2301 / \mathrm{sec}, \mathrm{mPa} . \mathrm{s})}$ & $4.68 \pm 0.45$ & $4.82 \pm 0.84$ & $4.76 \pm 0.23$ \\
\hline BV (115 1/sec, mPa.s) & $6.65 \pm 0.81$ & $6.35 \pm 1.35$ & $6.48 \pm 1.08$ \\
\hline BV (23 1/sec, mPa.s) & $7.74 \pm 1.22$ & $7.16 \pm 1.45$ & $7.17 \pm 0.95$ \\
\hline PV (mPa.s) & $1.23 \pm 0.11$ & $1.25 \pm 0.11$ & $1.22 \pm 0.12$ \\
\hline $\mathrm{SAP}(\mathrm{mmHg})$ & $133.2 \pm 21.56$ & $107.15 \pm 13^{a^{* * *}}$ & $103.6 \pm 13.61^{\mathrm{a}^{* * *}}$ \\
\hline DAP (mmHg) & $82.45 \pm 13.04$ & $68 \pm 7.49^{\mathrm{a}^{* * *}}$ & $65.05 \pm 9.29^{\mathrm{a}^{* * *}}$ \\
\hline MAP (mmHg) & $98.9 \pm 1.76$ & $81.25 \pm 8.4^{\mathrm{a}^{* * *}}$ & $79.1 \pm 9.77^{\mathrm{a}^{* * *}}$ \\
\hline Fibrinogen (mg/dl) & $257.76 \pm 89.34$ & $316.46 \pm 84.10^{\mathrm{a}^{* *}}$ & $294.07 \pm 93.29$ \\
\hline Total protein $(\mathrm{g} / \mathrm{dl})$ & $7.00 \pm 0.46$ & $6.74 \pm 0.54^{\mathrm{a}^{* *}}$ & $6.84 \pm 0.56$ \\
\hline Albumin (g/dl) & $4.33 \pm 0.35$ & $4.14 \pm 0.35^{\mathrm{a}^{* *}}$ & $4.18 \pm 0.30$ \\
\hline Total Cholesterol (mg/dl) & $173.25 \pm 48.33$ & $174.55 \pm 31.07$ & $183.30 \pm 44.73$ \\
\hline
\end{tabular}

Data are mean \pm SD, BV; Blood viscosity, PV; Plasma viscosity, Hct; Heamatocrit, SAP; Systolic Artery Pressure, DAP; Diastolic Artery Pressure, MAP; Mean Artery Pressure, ${ }^{\text {a }}$ Initial time vs $60^{\text {th }}$ min ., $120^{\text {th }}$ min., ${ }^{*} \mathrm{p}<0.05,{ }^{* *} \mathrm{p}<0.01,{ }^{* * *} \mathrm{p}<$ 0.001 .

Table 3. Hemoreologic and hematologic data for desflurane group

\begin{tabular}{|c|c|c|c|}
\hline & Initial Time & $60^{\text {th }} \cdot \min$ & $120^{\text {th }} \cdot \min$ \\
\hline Het $(\%)$ & $38.84 \pm 5.24$ & $37.62 \pm 4.92$ & $37.60 \pm 4.29$ \\
\hline BV (230 1/sec, mPa.s) & $4.20 \pm 0.98$ & $4.18 \pm 0.75$ & $4.17 \pm 0.68$ \\
\hline BV (115 1/sec, mPa.s) & $5.79 \pm 0.84$ & $5.60 \pm 0.91$ & $5.22 \pm 0.80^{\mathrm{a}^{* *}}$ \\
\hline BV (23 1/sec, mPa.s) & $6.70 \pm 1.20$ & $6.20 \pm 1.29^{\mathrm{a}^{*}}$ & $5.92 \pm 1.31^{\mathrm{a}^{* *}}$ \\
\hline \multicolumn{4}{|l|}{ Corrected Hct (45\%) } \\
\hline$\overline{\mathrm{BV}(2301 / \mathrm{sec}, \mathrm{mPa} . \mathrm{s})}$ & $4.72 \pm 0.20$ & $4.89 \pm 0.46$ & $4.82 \pm 0.54$ \\
\hline BV (115 1/sec, mPa.s) & $6.40 \pm 0.59$ & $6.35 \pm 0.67$ & $6.09 \pm 0.88$ \\
\hline BV (23 1/sec, mPa.s) & $7.39 \pm 0.85$ & $7.03 \pm 0.91$ & $6.52 \pm 1.65^{\mathrm{a}^{*}}$ \\
\hline $\mathrm{PV}(\mathrm{mPa} . \mathrm{s})$ & $1.24 \pm 0.86$ & $1.21 \pm 0.11^{\mathrm{a}^{* *}}$ & $1.23 \pm 0.11^{\mathrm{a}^{* *}}$ \\
\hline $\mathrm{SAP}(\mathrm{mmHg})$ & $127.65 \pm 26.91$ & $106.4 \pm 12.81^{a^{* *}}$ & $103.85 \pm 12.63^{\mathrm{a}^{* * *}}$ \\
\hline DAP (mmHg) & $80 \pm 11.73$ & $67.1 \pm 10.01^{\mathrm{a}^{* * *}}$ & $64.4 \pm 9.68^{\mathrm{a}^{* * *}}$ \\
\hline MAP (mmHg) & $98.95 \pm 11.83$ & $81.2 \pm 10.55^{\mathrm{a}^{* * *}}$ & $77.9 \pm 8.58^{\mathrm{a}^{* * *}}$ \\
\hline Fibrinogen (mg/dl) & $304.51 \pm 73.41$ & $309.25 \pm 64.13$ & $309.05 \pm 43.63$ \\
\hline Total protein $(\mathrm{g} / \mathrm{dl})$ & $7.09 \pm 0.66$ & $6.80 \pm 0.46^{\mathrm{a}^{* *}}$ & $6.94 \pm 0.55$ \\
\hline Albumin (g/dl) & $4.36 \pm 0.40$ & $4.18 \pm 0.26^{\mathrm{a}^{* *}}$ & $4.20 \pm 0.29$ \\
\hline Total Cholesterol (mg/dl) & $165.42 \pm 57.13$ & $167.10 \pm 55.15$ & $170.10 \pm 60.40$ \\
\hline
\end{tabular}

Data are mean \pm SD, BV; Blood viscosity, PV; Plasma viscosity, Hct; Heamatocrit, SAP; Systolic Artery Pressure, DAP; Diastolic Artery Pressure, MAP; Mean Artery Pressure, ${ }^{\mathrm{a}}$ Initial time vs $60^{\text {th }}$ min., $120^{\text {th }}$ min, ${ }^{*} \mathrm{p}<0.05,{ }^{* *} \mathrm{p}<0.01$, $* * * \mathrm{p}<0.001$

Table 4. The percentage of the blood viscosity changes in sevoflurane and desflurane group

\begin{tabular}{lcccc}
\hline & \multicolumn{2}{c}{ Group S } & \multicolumn{2}{c}{ Group D } \\
& $\mathbf{P}_{\mathbf{1}}(\mathbf{\%})$ & $\mathbf{P}_{\mathbf{2}}(\mathbf{\%})$ & $\mathbf{P}_{\mathbf{1}}(\mathbf{\%})$ & $\mathbf{P}_{\mathbf{2}}(\mathbf{\%})$ \\
\hline Native Hct (\%) & & & & \\
BV(230 1/sec, mPa.s) & $0.941 \pm 0.107^{*}$ & $0.957 \pm 0.082$ & $1.005 \pm 0.104$ & $0.986 \pm 0.131$ \\
BV(115 1/sec, mPa.s) & $0.900 \pm 0.113^{*}$ & $0.944 \pm 0.159$ & $0.968 \pm 0.091$ & $0.909 \pm 0.125$ \\
BV(23 1/sec, mPa.s) & $0.874 \pm 0.106^{*}$ & $0.904 \pm 0.119$ & $0.930 \pm 0.125$ & $0.886 \pm 0,136$ \\
Corrected Hct (45\%) & & & & \\
BV(230 1/sec, mPa.s) & $1.037 \pm 0.190$ & $1.026 \pm 0.102$ & $1.038 \pm 0.007$ & $1.022 \pm 0.108$ \\
BV(115 1/sec, mPa.s) & $0.957 \pm 0.184$ & $0.977 \pm 0.124$ & $0.994 \pm 0.084$ & $0.955 \pm 0.134$ \\
BV(23 1/sec, mPa.s) & $0.931 \pm 0.158$ & $0.936 \pm 0.109$ & $0.957 \pm 0.116$ & $0.881 \pm 0.211$ \\
PV (mPa.s) & $1.018 \pm 0.003$ & $0.991 \pm 0.008$ & $0.988 \pm 0.017^{* *}$ & $0.991 \pm 0.016$ \\
SAP (mmHg) & $0.807 \pm 0.033$ & $0.780 \pm 0.024$ & $0.844 \pm 0.079$ & $0.824 \pm 0.076$ \\
DAP (mmHg) & $0.829 \pm 0.041$ & $0.790 \pm 0.012$ & $0.838 \pm 0.002$ & $0.805 \pm 0.003$ \\
MAP (mmHg) & $0.820 \pm 0.070$ & $0.798 \pm 0.084$ & $0.820 \pm 0.891$ & $0.787 \pm 0.007$ \\
\hline Da $2 \mathrm{mHH}$
\end{tabular}

Data are mean \pm SD, Group S; Sevoflurane Group, Group D; Desflurane Group, BV; Blood viscosity, PV; Plasma viscosity, SAP; Systolic Arterial Pressure, DAP; Diastolic Arterial Pressure, MAP; Mean Arterial Pressure, $\mathrm{P}_{1}(\%) ; 60$ min/initial time, $\mathrm{P}_{2}(\%) ; 120 \mathrm{~min} /$ initial time, ${ }^{*} \mathrm{p}<0.05, * * \mathrm{p}<0.01$. 
Also the value of hematocrit showed meaningful decrease at $60^{\text {th }}(\mathrm{p}<0.05)$ and $120^{\text {th }} \mathrm{min}$. $(p<0.05)$ in the patients anesthetized with desflurane. The level of fibrinogen in patients anesthetized with Group $\mathrm{S}$ at $60^{\text {th }}$ min. $(\mathrm{p}<0.01)$ increased significantly. Unlike the results of the patients anesthetized with Group S, there was no a difference in the level of fibrinogen observed in the patients anesthetized with desflurane at any time. In addition, the level of albumin and protein in patients anesthetized with sevoflurane and desflurane at $60^{\text {th }} \mathrm{min}$. importantly decreased $(\mathrm{p}<0.01)$.

When we compared both the patients anesthetized with sevoflurane and desflurane, we did not find any statistical evidences for significant changes in the level of blood viscosity at three different shear rates, total protein, albumin, fibrinogen, total cholesterol at both $60^{\text {th }} \mathrm{min}$. and $120^{\text {th }}$ $\min$.

\section{Discussion}

The aim of our study is to investigate the effects of desflurane and sevoflurane on blood viscosity in different shear rates. Both anaesthetics agents have effects over blood viscosity via sympathetic blockade due to decreased hematocrit. The authors found that Group S had a negative effect on the blood viscosity, whereas desflurane produced stable effects on the blood circulation.

Sevoflurane and desflurane are the newly volatile anesthetics commonly used for the general anesthesia before the surgery. General anesthesia results in significant changes in the microvasculature involving primarily changes in the diameters of the arterioles and venules and combined changes in arterial pressure and the cardiac output [4,5]. The peripheral vascular effects of the anesthetics may influence the choice of anesthesia and may alter the results of experimental investigations performed in anesthetized animals. For this reason we have previously investigated the effects of these two volatile anesthetics on the deformability of erythrocytes which performed in young and old animals. These results revealed that even the desflurane anesthesia [18] and the sevoflurane anesthesia [2] has improved the deformability of erythrocytes in young animals, whereas it has impaired it in elderly animals [14].

Inhalation anaesthetics has several effects on different organ systems, like cardiovascular system, central nervous system, respiratory system, liver and kidney metabolism and neuromuscular pathways. Most studies have evaluated different characteristics of anaesthetic agent, and their comparisons of clinical manifestations over the organism. However, to our knowledge there has been no too many studies linking with the hemorheologic and hemostatic effects of volatile anaesthetic agents $[19,21]$.

Hemorheologic alternations are also important in term of anaesthesia. It is known that hemorheology is affected by many factors such as applied anaesthesia techniques, general or local use of anaesthetic agents, operation duration, duration and quantity of hemorrhage, infusion of crystalloid and macromolecular fluid, pain, hypothermia etc. [22-24]. In our study, we selected all the patients from those who had not any comorbidity and to undergo tympanoplasty, in order to provide patient standardization. Only one patient in Group S was ASA II because of Down syndrome. We tried to keep the parameters constant that might affect intraoperative rheology (MAC value, temperature, the amount of the intravenous fluid administered and bleeding quantity, etc.). In addition, all patients were received midazolam premedication that has been reported not to affect the blood viscosity in order to minimize the patients' anxiety [25].

Magora et al. [23] observed the effects of halothane, cyclopropane, thiopental and ketamine on blood viscosity. Their study showed that in patients who were exposed to the halothane and the cyclopropane, a significant decrease in the level of blood viscosity -especially in the $230 \mathrm{1} / \mathrm{sec}$ hematocrit and fibrinogen concentration is observed. During the thiopental anaesthesia, there was significant reduction in blood viscosity at $230 \mathrm{1} / \mathrm{sec}$ and in the level of hematocrit. During the ketamine anaesthesia, they did not found any statistically significant changes at the level of hematocrit, total protein, fibrinogen and blood viscosity at the different shear rates vs initial level. All those changes were explained with the effects of medicines to the sympathetic nervous system activity.

Hematocrit was one of the most important factors determining blood viscosity [9, 10, 22]. However the vessels smaller than $100 \mu \mathrm{m}$ (arteriole, capillary) are affected less than large vessels [8, 9]. In a review written by the guidance of these studies, Gordon et al. [22] reported that the most important parameters affecting blood rheology are peripheral vessel tone and hematocrit level as well as plasma viscosity and levels of fibrinogen and albumin, thus hematocrit alterations are inversely related to plasma volume. However, especially increase of the levels of hematocrit and fibrinogen has been reported to increase the predisposition to thrombosis [22].

In our study, we observed a decrease in blood viscosity at $231 / \mathrm{sec}$ in both groups. There was a decrease observed at $2301 / \mathrm{sec}$ in Group $\mathrm{S}$ group alone, and although no statistically significant difference was found between the groups in terms of capillary vessel viscosity, decrease in Group $\mathrm{S}$ compared to baseline value suggests that Group $\mathrm{S}$ is more effective on the capillary vessel viscosity. Whereas, effects of plasma viscosity is more determinant in the small vessels $[8,9,22]$. In addition, we believe that the differences found in inter-group comparison of the corrected hematocrit viscosities compared to the baseline values might have been resulted from the changes in plasma viscosity. These data of Yerer et. al. [19] are in compliance with ours, because considering the corrected viscosity values and the decrease in viscosity at the capillary level compared to baseline values. 
When our data are evaluated in the light of these findings, main cause of the decrease in the blood viscosity can be shown as anaesthetic agents to suppress the sympathetic nervous system activity. Viscosity decrease seen with both agents' results from sympatholytic effect differs in these agents. Desflurane has been reported to less suppress sympathetic activity, even induced it in high doses [4, 26]. Decrease in hematocrit value has been reported in the previous studies to be resulted from the peripheral congestion due to vasodilatation caused by sympathetic blockade [23, 24].

Plasma viscosity is a crucial determinant of whole blood viscosity [27]. Plasma is principal interface with the blood vessel wall because of the axial migration of RBCs in flowing blood. Consequently, it is possible to think that plasma viscosity directly affects endothelium [28, 29]. In many cohorts fibrinogen has been established as the major protein determinant of plasma viscosity. It is well known that plasma viscosity depends especially on plasma fibrinogen concentration, but also is affected by the concentration of other macromolecules, cholesterol and triglycerides [27, 30]. Microvascular blood flow is actively regulated in response to change in viscosity as a consequence of the level of shear stress developed in the endothelium [31]. Increased plasma viscosity restores shear stress in the microcirculation. Shear stress increases the rate of production of vasodilators (nitric oxide and prostacyclin) via mechanotransduction and has been associated with increased microvascular flow and capillary pressure [32]. Plasma viscosity in Group S increased by $1.02 \%$ at 60 minutes from baseline level with a significant degree, but decreased at 120 minutes by $0.99 \%$ in spite of the disappearance of significance. We can evaluate this statistical significant increase as increased plasma viscosity restores shear stress in the microcirculation. This change can be explained possibly with the change in plasma fibrinogen concentration. The decrease in plasma viscosity of Group D were $1.2 \%$ at 60 minute $(p<0.05)$ and $0.9 \%$ at 120 minute. Although there is no change statistically by means of plasma fibrinogen concentration, this change may be due to total protein and albumin levels. However, we did not observe a significant difference between the plasma viscosities. Nevertheless, we believe this is still a subject to be studied. When SAP, DAP and MAP values were investigated in accordance with the role of plasma viscosity in the regulation of systemic circulation and microcirculation, no statistical significance was found in two groups, but the changes among the groups in time were statistically significant. The change ratio of Group S and Group D at baseline and $60 \mathrm{~min}$ were calculated as \%19.3 and \%15.6 for SAP, \%17.1 and $\% 16.2$ for DAP and $\% 18$ and $\% 18$ for MAP. The change ratio of Group S and Group D at baseline and $120 \mathrm{~min}$ were calculated as $\% 22$ and $\% 17.6$ for SAP, $\% 21$ and $\% 19.5$ for MAP and $\% 20.2$ and $\% 21.3$ for MAP. In the review of Salazar et al. [33] stated that a negative correlation between whole blood viscosity and systolic blood pressure in the strong Heart Study. The evaluated data by considering the changes in plasma viscosity values are in the direction of lesser effect of desflurane over arterial pressure changes, in this way desflurane can facilitate the stabilization easily. Our study is consistent with the results of Ozarslan et al. [34].

In conclusion, decrease was found in the blood viscosity with both anaesthetic agents, mainly due to decreased hematocrit. This effect was primarily caused by the sympathetic blockade. The effects of potent volatile agents, specifically focusing on macrohemodynamics, have been investigated in clinical studies. In general, the decrease in blood pressure caused by volatile anesthetics is a direct result of the vasodilatation and depression of myocardial contractility and an indirect of the attenuation of sympathetic nervous system activity. The authors found that Group S had a negative effect on the blood viscosity, whereas desflurane produced stable effects on the blood macrocirculation [34]. In our opinion, desflurane might be a preferable anaesthetic agent. Further research is necessary to ascertain the effects on anaesthetics on the macromicrocirculation

Acknowledgments: This work was supported by the Scientific Research Projects Coordination Unit of Istanbul University. Project number:789.

Conflict of Interest: The authors declare no potential conflicts of interest with respect to the research, authorship, and/or publication of this article.

\section{References}

1. Trevor AJ, White PF. General Anesthetics, in: Katzung BG. (ed): Basic and clinical pharmacology.The Mac-Graw Hill Companies. 2007; Chapter 25.

2. Seagard JL, Bosnjak ZJ, Hopp FA, Jr Kampine JP. Cardiovascular effects of anaesthesia., in: Effects of anaesthesia, Covino BG, Fozzard HA, Rehder K, Strichartz G. (eds), Bethesda MD. American Physiological Society. 1985;149-177.

3. Seagard JL, Hopp FA, Donegan JH, Kalbfleisch JH, Kampine JP. Halothane and the carotid sinus reflex: evidence for multiple sites of action. Anesthesiology. 1982;57(3):191-202.

4. Weiskopf RB, Cahalan MK, Ionescu P, Eger EI, 2nd, Yasuda N, Lockhart SH, et al. Cardiovascular actions of desflurane with and without nitrous oxide during spontaneous ventilation in humans. Anesthesia and analgesia. 1991;73(2):165-74.

5. Weiskopf RB, Cahalan MK, Eger EI, 2nd, Yasuda N, Rampil IJ, Ionescu P, et al. Cardiovascular actions of desflurane in normocarbic volunteers. Anesthesia and analgesia. 1991;73(2):143-56.

6. Pagel PS, Warltier DC. Anaesthetics and left ventricular function, in: Ventricular function, Warltier DC. (ed). Baltimore, Williams \& Wilkins. 1995;213-252. 
7. Ebert TJ, Harkin CP, Muzi M. Cardiovascular responses to sevoflurane: a review. Anesthesia and analgesia. 1995;81(6 Suppl):S11-22

8. Isbister JP. Hyperviscosity: Clinical disorders, in Handbook of Hemorheology and Hemodynamics. Baskurt OK. (ed). IOS Press. 2007; 371-391.

9. Baskurt OK. Mechanisms of blood rheology alterations, in: Handbook of Hemorheology and Hemodynamics, Baskurt OK. (ed). IOS Press. 2007; 171-190.

10. Nash GB. Blood rheology and ischaemia. Eye. 1991;5 ( P 2):151-8.

11. Dupont J, Tavernier B, Ghosez Y, Durinck L, Thevenot A Moktadir-Chalons N, et al. Recovery after anaesthesia for pulmonary surgery: desflurane, sevoflurane and isoflurane. British journal of anaesthesia. 1999;82(3):355-9.

12. Welborn LG, Hannallah RS, Norden JM, Ruttimann UE, Callan CM. Comparison of emergence and recovery characteristics of sevoflurane, desflurane, and halothane in pediatric ambulatory patients. Anesthesia and analgesia. 1996;83(5):917-20.

13. Ozarslan NG, Ayhan B, Kanbak M, Celebioglu B Demircin $\mathrm{M}$, Ince $\mathrm{C}$, et al. Comparison of the effects of sevoflurane, isoflurane, and desflurane on microcirculation in coronary artery bypass graft surgery. Journal of cardiothoracic and vascular anesthesia. 2012;26(5):791-8.

14. Yerer MB, Aydogan S, Comu FM. Gender-related alerations in erythrocyte mechanical activities under desflurane or sevoflurane anesthesia. Clinica hemorheology and microcirculation. 2008;39(1-4):423-7.

15. Baskurt OK, Boynard M, Cokelet GC, Connes P, Cooke $\mathrm{BM}$, Forconi S et al. New guidelines for hemorheologica laboratory techniques. International Expert Panel for Standardization of emorheological Methods. Clin Hemorheol and Microcirc. 2009;42,75-97.

16. Matrai A, Whittington BBW, Ernst E. A simple method of estimating whole blood viscosity at standardized hematocrit. Clin Hemorheol. 1987;7, 261-265.

17. Harkness J. A new instrument for the measurement of plasma-viscosity. Lancet. 1963;2(7302):280-1.

18. Lenz C, Rebel A, Waschke KF, Koehler RC, Frietsch T Blood viscosity modulates tissue perfusion: sometimes and somewhere. Transfusion alternatives in transfusion medicine : TATM / NATA, Network for Advancement of Transfusion Alternatives. 2008;9(4):265-72.

19. Yerer MB, Aydogan S, Comu FM, Arslan M, GunesEkinci I, Kurtipek O, et al. The red blood cell deformability alterations under desfluran anesthesia in rats. Clinical hemorheology and microcirculation. 2006;35(1-2):213-6

20. Iannuzzi E, Iannuzzi M, Viola G, Cerulli A, Cirillo V Chiefari M. Desflurane and sevoflurane in elderly patients during general anesthesia: a double blind comparison. Minerva anestesiologica. 2005;71(4):147-55.
21. Merin RG. Physiology, pathophysiology and pharmacology of the coronary circulation with particular emphasis on anesthetics. Anaesthesiologie und Reanimation. 1992;17(1):5-26.

22. Gordon RJ, Ravin MB. Rheology and anesthesiology. Anesthesia and analgesia. 1978;57(2):252-61

23. Magora F, London M, Eimerl D, Aronson HB. Blood viscosity during anaesthesia with halothane, cyclopropane, thiopentone and ketamine. British journal of anaesthesia. 1974;46(5):343-7.

24. Odoom JA, Bovill JG, Hardeman MR, Oosting J, Zuurmond WW. Effects of epidural and spinal anesthesia on blood rheology. Anesthesia and analgesia. 1992;74(6):835-40

25. Erdogan C, Erdem A, Akinci SB, Dikmenoglu N, Basgul E, Balkanci ZD, et al. The effect of midazolam on erythrocyte deformability and plasma viscosity in rats: A158. Eur J Anaesth. 2005;22,43-44.

26. Ebert TJ, Muzi M. Sympathetic hyperactivity during desflurane anesthesia in healthy volunteers. A comparison with isoflurane. Anesthesiology. 1993;79(3):444-53.

27. Kesmarky G, Kenyeres P, Rabai M, Toth K. Plasma viscosity: a forgotten variable. Clinical hemorheology and microcirculation. 2008;39(1-4):243-6.

28. Salazar Vazquez BY, Cabrales P, Tsai AG, Intaglietta M. Nonlinear cardiovascular regulation consequent to changes in blood viscosity. Clinical hemorheology and microcirculation. 2011;49(1-4):29-36.

29. Tomiyama Y, Brian JE, Jr., Todd MM. Plasma viscosity and cerebral blood flow. American journal of physiology Heart and circulatory physiology. 2000;279(4):H1949-54.

30. Rosenson RS, Lowe GD. Effects of lipids and lipoproteins on thrombosis and rheology. Atherosclerosis. 1998;140(2):271-80.

31. Cabrales P, Tsai AG. Plasma viscosity regulates systemic and microvascular perfusion during acute extreme anemic conditions. American journal of physiology Heart and circulatory physiology. 2006;291(5):H2445-52.

32. Cabrales $P$, Intaglietta $M$, Tsai AG. Increase plasm viscosity sustains microcirculation after resuscitation from hemorrhagic shock and continuous bleeding. Shock. 2005;23(6):549-55

33. Salazar Vazquez BY, Martini J, Chavez Negrete A, Cabrales P, Tsai AG, Intaglietta M. Microvascular benefits of increasing plasma viscosity and maintaining blood viscosity: counterintuitive experimental findings. Biorheology. 2009;46(3):167-79.

34. Ozarslan NG, Ayhan B, Kanbak M, Celebioglu B, Demircin $\mathrm{M}$, Ince $\mathrm{C}$, et al. Comparison of the effects of sevoflurane, isoflurane, and desflurane on microcirculation in coronary artery bypass graft surgery. Journal of cardiothoracic and vascular anesthesia. 2012;26(5):791-8. 